were stronger in response to a stimulus than muscles that had received non-treated stem cells.

Nature Med. http://doi.org/rhg; http://doi.org/rhh (2014)

\section{ANIMAL BEHAVIOUR}

\section{Picky spiders prefer virgins}

Male black widow spiders

(Latrodectus hesperus)

prefer their female mates to

be healthy and chaste - a

rare demonstration of mate

selection by males.

Emily MacLeod and Maydianne Andrade at the University of Toronto Scarborough, Canada, studied whether male black widows are fussy about females. Males overwhelmingly chose to mate with well-fed females who had not previously mated, both in controlled field studies and in the wild.

Male spiders' preference for well-fed virgins could be strong enough to cause females to have evolved traits, such as the production of sex pheromones, that entice males and advertise the female's status, say the authors.

Anim. Behav. 89, 163-169 (2014)

\section{CANCER}

\section{Unmasking the real risk genes}

Cancer researchers have found part of the answer in the case of the 'missing heritability' the mismatch between genetic disease risk and common genetic variants.

It has long been thought that common variants might be weakly linked to disease because they are co-inherited with rare, nearby genetic variants. These variants are much more predictive of disease, but are themselves too rare to be discovered, even in studies with large sample sizes.

Zsofia Kote-Jarai of the Institute for Cancer Research in Sutton, UK, and her colleagues report the first evidence for this 'synthetic association' in cancer. They show that four common genetic variants in or near the HOXB13 gene are associated with a roughly $30 \%$ increase in cancer risk and are almost always inherited with a rare gene variant, which itself predicts an approximately $400 \%$ increase in risk for the disease.

PLoS Genet. 10, e1004129 (2014)

\section{CONSERVATION}

\section{Birds should fear windows}

Collisions with windows are the second-largest humanrelated source of US bird mortality (after house cats), with low-rise buildings and homes responsible for most deaths.

Scott Loss of the Smithsonian Conservation Biology Institute in Washington DC and his colleagues examined 23 studies of bird collisions, allowing them to estimate that between 365 million and 988 million birds are killed every year by hitting buildings.

Despite the problem of bird strikes on skyscrapers being well publicized, the team found that these impacts represented less than $1 \%$ of deaths.

Several bird species, including the goldenwinged warbler (Vermivora chrysoptera) and the painted bunting (Passerina ciris) were particularly collision-prone. Condor 116, 8-23 (2014)

\section{MATERIALS \\ A bulk graphene mimic}

Physicists have identified a material that can conduct efficiently in multiple layers.

After the rush of interest in the atom-thick layers of carbon known as graphene, materials scientists turned to metal dichalcogenides - layered compounds that are also good conductors of electrical current. Rhenium disulphide now joins the promising candidates in this family.

Junqiao Wu at the Lawrence Berkeley National Laboratory in California and his colleagues

COMMUNITY CHOICE

The most viewed papers in science

\title{
Conflicts mar studies of sweet drinks
}

\section{A HIGHLY READ \\ on plosmedicine.org 13 Jan-12 Feb}

Maira Bes-Rastrollo of the University of Navarra in Pamplona, Spain, and her colleagues combed three databases for systematic reviews about the association between sugarsweetened beverages and weight gain. The team found 18 conclusions in 17 such reviews, and 6 of those papers contained disclosures of financial ties to the food industry.

Of the 12 conclusions that had no reported financial conflict of interest, $83.3 \%$ said that consumption of sugarsweetened beverages could be a risk factor for weight gain. But the same percentage of conclusions with a reported financial tie to industry said that there was insufficient evidence of a link.

PLoS Med. 10, e1001578 (2014)

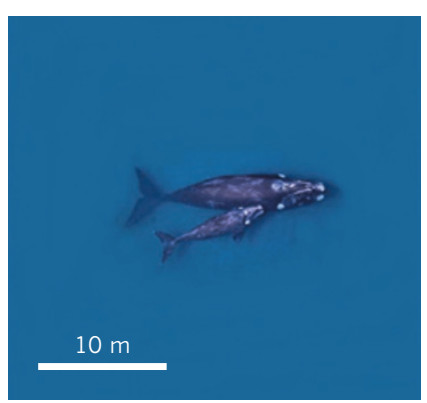

discovered that bulk samples of the material have a direct bandgap, a gap in energy levels that can be used to absorb or emit light efficiently. Other members of the family have this type of bandgap only when isolated in monolayers. Nature Commun. 5, 3252 (2014)

\section{REMOTE SENSING}

\section{Counting whales from space}

Researchers have for the first time counted whales from space, tallying 55 "probable" southern right whales and several other whale-like objects off the coast of Argentina.

Peter Fretwell and colleagues at the British Antarctic Survey in Cambridge, UK, analysed a single high-resolution WorldView2 satellite image

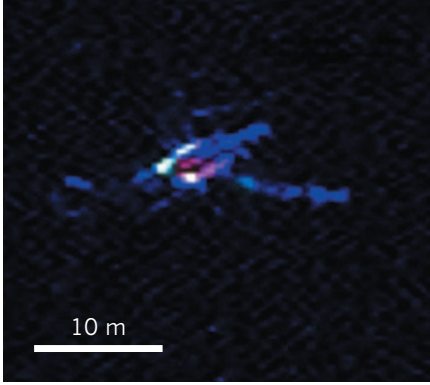

(pictured, right; an aerial photograph is shown for comparison, left) from Earth-imagery company DigitalGlobe. The image covered Península Valdés, a breeding area for a major population of southern right whales (Eubalaena australis).

The team found that all nine available spectra could reliably identify whales at the surface, and a far-blue 'coastal band' that penetrates deeper into the water pinpointed possible whales below the surface. An automated detection system found $89 \%$ of the whales that had been classified manually as probable sightings.

PLoS ONE 9, e88655 (2014)

\section{$\checkmark$ NATURE.COM}

For the latest research published by Naturevisit:

www.nature.com/latestresearch 